\title{
Late gestation undernutrition can predispose for visceral adiposity by altering fat distribution patterns and increasing the preference for a high-fat diet in early postnatal life
}

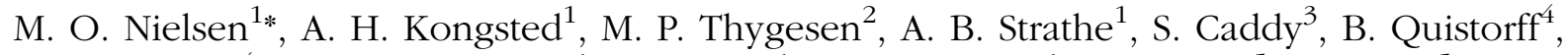 \\ W. Jørgensen ${ }^{4}$, V. G. Christensen ${ }^{1}$, S. Husted ${ }^{1}$, A. Chwalibog ${ }^{1}$, K. Sejrsen ${ }^{5}$, S. Purup ${ }^{5}$, E. Svalastoga ${ }^{1}$, \\ F. J. McEvoy ${ }^{1}$ and L. Johnsen ${ }^{1}$ \\ ${ }^{1}$ Department of Clinical Veterinary and Animal Sciences, Faculty of Health and Medical Sciences, University of Copenhagen, \\ DK 1870 Frederiksberg C, Denmark \\ ${ }^{2}$ Cook Medical Europe APS, Bjaeverskov, Denmark \\ ${ }^{3}$ Swayne E Partners Veterinary Surgeons, Suffolk, UK \\ ${ }^{4}$ Department of Biomedical Sciences, Nuclear Magnetic Resonance Centre, Faculty of Health and Medical Sciences, \\ University of Copenhagen, Copenhagen, Denmark \\ ${ }^{5}$ Department of Animal Science, Faculty of Science and Technology, Aarbus University, Aarbus, Denmark
}

(Submitted 7 September 2011 - Final revision received 10 August 2012 - Accepted 13 August 2012 - First published online 12 October 2012)

\section{Abstract}

We have developed a sheep model to facilitate studies of the fetal programming effects of mismatched perinatal and postnatal nutrition. During the last trimester of gestation, twenty-one twin-bearing ewes were fed a normal diet fulfilling norms for energy and protein (NORM) or $50 \%$ of a normal diet (LOW). From day 3 postpartum to 6 months (around puberty) of age, one twin lamb was fed a conventional (CONV) diet and the other a high-carbohydrate-high-fat (HCHF) diet, resulting in four groups of offspring: NORM-CONV; NORMHCHF; LOW-CONV; LOW-HCHF. At 6 months of age, half of the lambs (all males and three females) were slaughtered for further examination and the other half (females only) were transferred to a moderate sheep diet until slaughtered at 24 months of age (adulthood). Maternal undernutrition during late gestation reduced the birth weight of LOW offspring $(P<0 \cdot 05)$, and its long-term effects were increased adrenal size in male lambs and adult females $(P<0.05)$, increased neonatal appetite for fat- $(P=0.004)$ rather than carbohydrate-rich feeds $(P<0.001)$ and reduced deposition of subcutaneous fat in both sexes $(P<0.05)$. Furthermore, LOW-HCHF female lambs had markedly higher visceral:subcutaneous fat ratios compared with the other groups $(P<0 \cdot 001)$. Postnatal overfeeding (HCHF) resulted in obesity ( $>30 \%$ fat in soft tissue) and widespread ectopic lipid deposition. In conclusion, our sheep model revealed strong pre- and postnatal impacts on growth, food preferences and fat deposition patterns. The present findings support a role for subcutaneous adipose tissue in the development of visceral adiposity, which in humans is known to precede the development of the metabolic syndrome in human adults.

Key words: Fetal and postnatal programming: Growth: Food preference: Obesity

Individuals subjected to intra-uterine growth restriction (IUGR) are often born smaller-for-gestational age and with asymmetric body proportions ${ }^{(1,2)}$, and have an increased risk of developing welfare diseases such as type 2 diabetes, obesity and cardiovascular disorders ${ }^{(3-5)}$. This led Hales \& Barker ${ }^{(6)}$ to propose the 'thrifty phenotype hypothesis' which suggests a fetal programming effect of IUGR on adult health and disease.

Restricted fetal growth might be an immediate adaptation to adverse intra-uterine conditions giving the individual a better chance of survival to term ${ }^{(7)}$. The growth and development of crucial organs such as the brain may be spared, while the fetal growth of most other organs, such as the pancreas, liver and kidneys ${ }^{(8,9)}$ and skeletal muscle is arrested, and low- and birth-weight individuals are generally born with less lean body mass ${ }^{(10,11)}$ than controls. In evolutionary terms, this makes good sense, as it might be 'safer' to spare muscle growth and invest in fat deposition, thereby developing what has been termed a 'thin-fat phenotype', to increase

Abbreviations: CONV, conventional diet; CT, computer tomography; HCHF, high-carbohydrate-high-fat diet; IUGR, intra-uterine growth restriction; LOW, $50 \%$ of normal diet; NORM, normal diet.

*Corresponding author: M. O. Nielsen, fax +45353 33020, email mon@life.ku.dk 
the chances of survival in the immediate postnatal period $^{(12,13)}$.

In humans and animals, IUGR can also predispose for a greater allocation of fat postnatally in the visceral adipose tissue of young individuals ${ }^{(14-16)}$. In humans, it is now

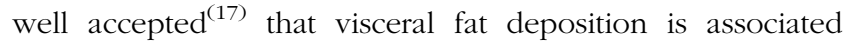
with an increased risk of later development of metabolic dysfunctions, but this obviously depends on postnatal nutrition exposure.

Postnatal dietary effects have been extensively investigated in human subjects and animals born with body weights normal-for-gestational age. As expected, postnatal food intake and weight gain are highly correlated with adiposity in later life ${ }^{(18,19)}$, and high dietary intake in the very early postnatal period is a particular risk factor, as it has been reported in the rat ${ }^{(20)}$.

Much less is known about postnatal dietary effects on individuals who have been subjected to IUGR. In rats, exposure to prenatal energy or protein restriction has been shown to increase food intake postnatally, resulting in hyperphagia, accelerated weight gain and catch-up growth ${ }^{(21)}$. In addition, there are also indications from animal models that prenatal programming can have an impact on appetite regulatory systems in sheep ${ }^{(22)}$ and alter food preferences in postnatal life in rats in favour of high-fat foods ${ }^{(23)}$.

It remains to be established, however, to what extent dietary corrections introduced later in postnatal life could be used as an intervention to prevent or overcome developmental and metabolic disorders caused by the unfavourable interactive effects of fetal and early postnatal nutrition, and therefore whether special nutritional recommendations would be appropriate for individuals born small-for-gestational age.

The majority of studies on fetal programming have been conducted with rodents (rats and mice) as experimental models, but great care must be taken in making direct comparisons between rodents and humans in the perinatal period. The rodent pup is born altricial, whereas the human baby is born physiologically precocial. Thus, the final development and maturation of organs such as the brain and gut take place in the rodent pup during the first weeks of life (the 'lactation' period), whereas in the human fetus it occurs during the last trimester of 'gestation'(24). The interactive effects of late gestational and early postnatal nutrition are therefore difficult to translate from rodents to humans. Other animal models are therefore needed with gestation periods, litter sizes and offspring maturity at birth that are more similar to humans in order to supplement and verify findings during this period of development. For this important reason, we set out to develop an experimental animal model based on sheep, which will allow us to study the mechanisms involved in developmental changes, and metabolic and endocrine function in a lifetime perspective depending on the interactions between nutrition exposures in late gestation and early postnatal life. The nutrition exposure in postnatal life includes a (for a ruminant animal extreme) high-carbohydrate-high-fat diet. The late gestation period has due to animal model restrictions not received as much attention in fetal programming research, but it is a challenging period where the quantitative development of the fetus takes place in both humans and ovines. Organogenesis is generally concluded, but maturation of several organs and endocrine systems takes place during this period, such as muscle growth ${ }^{(25)}$, endocrine pancreas maturation $^{(26)}$ and the hypothalamic appetite regulatory system $^{(27)}$

In the present study, we present this new Copenhagen sheep model and the outcomes of a first study addressing the hypotheses that: (1) late-gestational undernutrition programmes for increased appetite and preference for high-fat food in the offspring in early postnatal life, thereby predisposing for obesity; (2) prenatally undernourished offspring have altered fat deposition patterns, favouring visceral obesity following exposure to an unhealthy diet in early postnatal life; (3) dietary corrections made later in postnatal life to overcome adiposity developed in early life are more effective in individuals who have undergone a normal fetal development than in individuals who were exposed to late gestational malnutrition.

\section{Materials and methods}

All experimental animal handling and procedures were approved by the Danish National Committee on Animal Experimentation and conducted at the experimental farm Rørrendegård of the Faculty of Health and Medical Sciences, University of Copenhagen, Denmark.

\section{Experimental animals and experimental design}

Offspring of both sexes from twin-pregnant Shropshire sheep (mated with the same Shropshire ram and with parities ranging from 2 to 6 ) were used in this $2 \times 2$ factorial design experiment with two late-gestational and two early-postnatal nutritional treatments (Fig. 1).

\section{Feeding and housing of twin-pregnant sheep}

Twin-pregnant sheep ( $n$ 21) were fed either a normal diet (NORM, $n$ 10) consisting of silage plus a commercial concentrate supplement (Fårekraft T; Lærkegården) during the last 6 weeks of gestation (term $147 \mathrm{~d}$ ) in accordance with requirements specified by the National Research Council ${ }^{(28)}$ for digestible energy and digestible crude protein, or a $50 \%$ of normal diet (LOW, $n$ 11) with silage and concentrate provision equivalent to $50 \%$ of the amount (per kg ${ }^{0.75}$ ) offered to NORM-fed sheep, i.e. an overall undernutrition of $50 \%$ with respect to energy and protein (Table 1). LOW sheep were offered small daily amounts of barley straw to avoid discomfort from hunger. The sheep were fed at 07.30 and 15.30 hours, half the ration being given at each feeding. They were housed in sawdust-bedded individual bar-walled pens $(1.5 \times 3 \mathrm{~m})$ in the same barn. Before lambing, they were fitted with an udder cover to prevent the newborn lambs from suckling. The sheep were milked by hand $3 \mathrm{~h}$ after parturition with the aid of oxytocin $(200 \mathrm{mU}$ oxytocin in $1 \mathrm{ml}$ saline given intravenously just before milking), colostrum was sampled and the yield determined, and each lamb subsequently received $200 \mathrm{ml}$ colostrum by a stomach tube to 


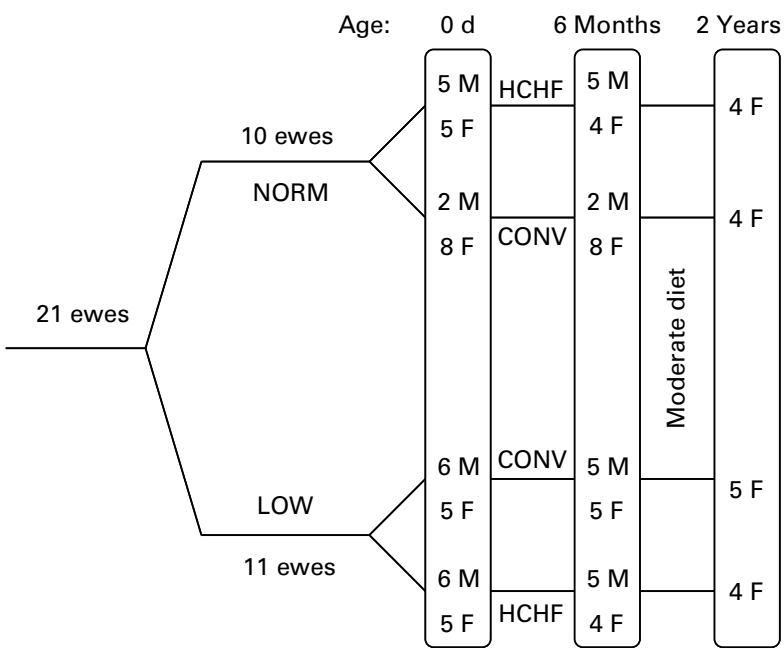

Fig. 1. Study design. The experimental animals were offspring of twin-pregnant sheep exposed to $100 \%$ (NORM) or $50 \%$ (LOW) of energy and protein requirements during the last 6 weeks of gestation (term $147 \mathrm{~d}$ ). The twin offspring were assigned to each their experimental diet from $3 \mathrm{~d}$ to 6 months postpartum, either a conventional hay diet (CONV) adjusted to achieve moderate growth rates, or a high-carbohydrate-high-fat diet $(\mathrm{HCHF})$. The number of animals and sex (M, males; $F$, females) at different time points ( $t=0 \mathrm{~d}, 6$ months and 2 years of age) are shown. All twin-pregnant sheep gave birth to two live lambs (the experimental animals) at term. Two lambs died for no obvious reasons $2 \mathrm{~d}$ after birth (one NORM-HCHF and one LOW$\mathrm{HCHF}$ ), and two more lambs died from acute diarrhoea at 3-4 weeks of age (one LOW-HCHF and one LOW-CONV). A total number of forty-two offspring were included in registrations at birth, and thirty-eight lambs were included in registrations thereafter. By the end of the experimental postnatal feeding period (about 6 months of age), two more lambs died as adolescents acutely without any prior health problems and for reasons not caused by the experimental feedings (one LOW-HCHF after adrenaline challenge and one LOWCONV due to acute systemic infection after a catheter removal). Data from these two older animals were included until the week before they died, just before the slaughtering at 6 months of age. No other health problems were detected, and no antibiotic or other treatments were given to any of the experimental animals at any time point during the experiment.

ensure good passive immunisation; thereafter, the lambs were allowed to suckle the dams freely. After parturition, all sheep were fed ad libitum with the pre-partum diet. They were removed from their lambs $3 \mathrm{~d}$ postpartum, the pens were subdivided, and thereafter the lambs were individually housed.

\section{Feeding and housing of lambs during postnatal dietary treatments (3d-6 months of age)}

The two lambs from each twin pair were assigned to different postnatal feeding regimens from day 3 to 6 months postpartum, either a conventional diet (CONV, $n$ 21) or a high-carbohydrate-high-fat diet ( $\mathrm{HCHF}, n$ 21), thereby resulting in four experimental groups in our Copenhagen sheep model: NORM-CONV ( $n$ 10); NORM-HCHF ( $n$ 10); LOW-CONV ( $n$ 11); LOW-HCHF ( $n$ 11). When allocating lambs to the postnatal feeding groups, it was attempted to obtain as even a distribution of sex and birth weight across the four different experimental groups as possible. The CONV-fed lambs in the milk-feeding period (from day 3 to 8 weeks of age) received a commercial milk replacer (200 g milk replacer/ litre water, Friska Sød; DLG amba), and were fed artificially dried green hay of the quality 'very high' from 2 weeks of age (Tjørnehøj Mølle). Throughout the period of differential feeding (from day 3 to 6 months of age), milk and hay allowances were fed restrictedly, and daily allowances were adjusted for individual lambs on a weekly basis to maintain moderate-for-the-breed live weight gains of approximately $250 \mathrm{~g} / \mathrm{d}$.

The HCHF lambs in the milk-feeding period (from day 3 to 8 weeks of age) received milk replacer (ad libitum until a maximum allowance of 2 litres/d was reached), dairy cream (Osted ost og mejeri APS; 38\% fat in DM; ad libitum until a maximum allowance of 0.5 litres/d was reached) and popped maize (Tjørnehøj Mølle; ad libitum until a maximum allowance of $1 \mathrm{~kg} / \mathrm{d}$ was reached) supplemented with barley straw ad libitum (negligible contribution to energy and protein intake). The cream and milk replacer were delivered by bottle until lambs had learnt to drink from a suckling bucket. After weaning (from 8 weeks to 6 months of age), the HCHF lambs were fed 0.5 litres/d dairy cream mixed with 0.5 litres/d milk replacer and offered $1 \mathrm{~kg} / \mathrm{d}$ popped maize. The compositions of the feedstuffs are shown in Table 1 .

The HCHF diet was designed to ensure that a substantial part of the ingested feed would escape forestomach fermentation and be digested in the abomasum and intestines, as in monogastrics. The high-fat dairy cream supplement was administered in liquid form from a suckling bucket to elicit the so-called oesophageal groove reflex, where muscle flaps in the rumen wall 'close' to form a tube allowing the ingested liquid to bypass rumen fermentation and be transported directly from the oesophagus into the lower segments of the gut $^{(29,30)}$. Visual inspection of the gut content after slaughter at 6 months of age confirmed that ingested milk and cream in the HCHF lambs were present in the lower segments of the gut shortly after feeding. Maize starch has a rather low degradability in the forestomachs of ruminant animals ${ }^{(31,32)}$, and starch escaping foregut fermentation can undergo digestion in the small intestine and be absorbed as glucose.

From 23 weeks of age until slaughter at about 26 weeks of age, all animals were subjected to acute metabolic and endocrine tolerance tests (not reported here, but comprising intravenous bolus injections on separate days with glucose, insulin or adrenalin, and a $2 \mathrm{~d}$ fasting challenge), and were placed in open-air respiratory chambers for measurements of gaseous

Table 1. Chemical composition and digestible energy (DE) content of the experimental feeds

\begin{tabular}{|c|c|c|c|c|c|c|}
\hline & \multicolumn{2}{|c|}{$\begin{array}{l}\text { Percentage } \\
\text { in feed }\end{array}$} & \multicolumn{3}{|c|}{ Percentage in DM } & \multirow[b]{2}{*}{$\mathrm{DE} / \mathrm{kg} \mathrm{DN}$} \\
\hline & $\mathrm{DM}$ & Ash & C fibre & $\mathrm{CP}$ & $C$ fat & \\
\hline Silage & $61 \cdot 3$ & 0.83 & $16 \cdot 1$ & $6 \cdot 0$ & NA & $12 \cdot 8$ \\
\hline $\begin{array}{l}\text { Fårekraft } \\
\text { (concentrate) }\end{array}$ & 88.5 & 1.73 & 9 & 30 & 5 & $15 \cdot 2$ \\
\hline Hay & 91.8 & 0.64 & $26 \cdot 2$ & $23 \cdot 7$ & 3.9 & 14.0 \\
\hline Maize & 88 & 0.13 & $1 \cdot 2$ & 7.7 & 3.7 & $16 \cdot 3$ \\
\hline Milk powder & 95 & 0.72 & 0.01 & 24 & 19 & $19 \cdot 7$ \\
\hline Milk & 19 & 0.72 & 0 & $4 \cdot 8$ & 3.8 & $19 \cdot 7$ \\
\hline Cream & $42 \cdot 9$ & 0.12 & 0 & $2 \cdot 1$ & 38 & 30.5 \\
\hline
\end{tabular}

C fibre, crude fibre; $\mathrm{CP}$, crude protein; $\mathrm{C}$ fat, crude fat; NA, not available. 
exchange. At 1 week after conclusion of these tests and measurements, half of the 6-month-old (around puberty) animals from each feeding group were slaughtered, being a total of nineteen animals (all of the sixteen males and three of the females).

Throughout the study, all animals (sheep and lambs) had free access to water and a vitamin-mineral mix (Maxcare Sheep Pre Lamb Minerals; Trouw Nutrition International).

The daily ration was delivered in two meals each day given at 07.30 and 15.30 hours, except for lambs during the first $8 \mathrm{~d}$ of bottle feeding, which were fed four times each day.

\section{Feeding and management of females from adolescence to young adulthood}

Only female adolescent offspring ( $n$ 17) continued in the experiment after 6 months of age, and from this point onwards, they were managed as a single flock and all were fed the same moderate level, grass-based diet (pasture during summer, silage indoors during winter) until conclusion of the experiment at an age of approximately 24 months.

\section{Feed intake and body weight recordings}

Feed intake was recorded over a $24 \mathrm{~h}$ period once weekly in twin-pregnant sheep. In offspring, intake of individual feedstuffs was recorded daily during the milk feeding period (from day 3 to 8 weeks of age), and once weekly thereafter until the end of the experimental postnatal feeding period at 6 months of age.

Body weights were determined at birth and weekly thereafter until 23 weeks of age and at 1 and 2 years of age in the live female animals. Body proportions (crown-rump length, girth circumference, height over withers and head circumference) were measured at days 1, 3 and 8, at 22 weeks of age, and at 1 and 2 years of age.

\section{Slaughter of the experimental animals}

Animals slaughtered at 6 months of age received Fentanyl (Dumex-Alpharma; $5 \mu \mathrm{g} / \mathrm{kg}$ body weight intravenously) for pain relief, were anaesthetised with Rapinovet ${ }^{\circledR}$ (ScheringPlough; induction with an intravenous injection of $2 \mathrm{mg}$ propofol/kg body weight) and were finally exsanguinated. The animals slaughtered at 24 months of age were killed by captive bolt stunning followed by exsanguination. Immediately after exsanguination, the different organs were excised and weights recorded. Subcutaneous back fat layer thickness was determined above the muscularis. longissimus dorsi at the level of the last rib after storage of carcasses overnight in a cold room at $4^{\circ} \mathrm{C}$.

\section{Open-air calorimetry}

At 6 months and 2 years of age, animals were placed in metabolism cages and respiratory gaseous exchange was measured during a $22 \mathrm{~h}$ period in an open-air circuit system (temperature $15-18 \cdot 8^{\circ} \mathrm{C}$, humidity $65-75 \%, 12 \mathrm{~h}$ light-dark cycle) consisting of two respiration chambers, as described by Chwalibog et $a l{ }^{(33)}$. Respiratory quotients were calculated as total $\mathrm{CO}_{2}$ production divided by total $\mathrm{O}_{2}$ consumption.

\section{Computer tomography scanning}

At 6 months and 2 years of age, the seventeen live female lambs were subjected to computer tomography (CT) examination using a single-slice helical CT scanner (Siemens), and were sedated during scannings with Domitor ${ }^{\circledR}$ vet (Orion Pharma Animal Health; 0.02 mg Medetomidin/kg intramuscularly) and Ketaminol ${ }^{\circledR}$ vet (Intervet; 0.8 mg Ketamin $/ \mathrm{kg}$ intramuscularly). A region from the level of the thoracic inlet to the hip joints was included. Slice thickness was $8 \mathrm{~mm}$, and scan time was approximately $80 \mathrm{~s}$ per scan. Images were processed using a filter favouring contrast resolution. Histograms showing the frequency of occurrence of each CT number (measured in Hounsfield units) in all image slices were used to determine the relative proportions of image pixels that displayed adipose tissue to those that displayed non-adipose soft (lean) tissue as reported previously ${ }^{(34)}$. Semi-automated image analysis techniques described previously ${ }^{(35)}$ were used to determine the thickness of subcutaneous adipose tissue on particular image slices.

\section{Mitogenic activity and insulin growth factor I content in the colostrum}

Concentration of insulin growth factor I in whey fractions prepared from the colostrum sampled from sheep $3 \mathrm{~h}$ after parturition was determined using non-competitive time-resolved immunofluorometric assays of the sandwich type validated for cow serum and milk samples, as described previously ${ }^{(36)}$ The mitogenic activity of whey prepared from colostrum samples was determined using a sensitive cell-based screening assay with mammary epithelial cells ${ }^{(37)}$, which has previously been used for determining the biological activity of bovine milk including colostrum samples ${ }^{(38)}$. Treatment media were prepared from the colostrum from nineteen individual sheep by adding concentrations of $0 \cdot 01,0 \cdot 1,0 \cdot 5,1,2.5$ and $5 \%$ of whey samples to culture medium with three replicates per sample, and mitogenic activity of whey samples was determined using incorporation of [methyl- $\left.{ }^{3} \mathrm{H}\right]$ thymidine $(\mathrm{dpm} /$ well) as a measure of DNA synthesis ${ }^{(37)}$. Results were adjusted to a similar scale by dividing values for [methyl- ${ }^{3} \mathrm{H}$ ] thymidine incorporation per well by the average basal value for incorporation in each assay.

\section{Statistical analyses}

All statistical models were derived from the same linear mixed model:

$$
y=x \beta+Z b+e
$$

where y is a $N$-dimensional vector of observations; $\mathrm{X}$ is a $N \times p$ design matrix for the fixed effects; $\beta$ is a $P$-dimensional vector of fixed-effects parameters; $\mathrm{Z}$ is a $N \times q$ design matrix for the random effects; $b$ is a $q$-dimensional vector of 
Table 2. Daily energy and protein intake of twin-pregnant sheep during the last 6 weeks of gestation (term $147 \mathrm{~d}$ ) and sex distribution and birth weights of their offspring

(Least square means (LSMEAN) with their standard errors except feed requirements which are presented as a range)

\begin{tabular}{|c|c|c|c|c|}
\hline \multirow[b]{2}{*}{ Late-gestation nutrition group of the pregnant sheep } & \multicolumn{2}{|c|}{ NORM } & \multicolumn{2}{|c|}{ LOW } \\
\hline & LSMEAN & SEM & LSMEAN & SEM \\
\hline Numbers of ewes in the experiment & \multicolumn{2}{|c|}{10} & \multicolumn{2}{|c|}{11} \\
\hline Body weight of ewes (kg, 6 weeks pre-partum) & $78 \cdot 5^{\mathrm{a}}$ & 1.6 & $71.5^{\mathrm{b}}$ & $2 \cdot 6$ \\
\hline BCS of ewes (6 weeks pre-partum) & $4 \cdot 25$ & 0.22 & 3.77 & 0.23 \\
\hline DE (MJ/d, last 6 weeks pre-partum) & $20 \cdot 14^{x}$ & $2 \cdot 83$ & $10 \cdot 78^{y}$ & 3.68 \\
\hline Norm for $\mathrm{DE}(\mathrm{MJ} / \mathrm{d} \text {, last } 6 \text { weeks pre-partum })^{*}$ & \multicolumn{4}{|c|}{ Increasing from 19.6 to 20.5} \\
\hline DCP intake (g/d, last 6 weeks pre-partum) & $164 \cdot 99^{\mathrm{x}}$ & 23.87 & $88 \cdot 25^{y}$ & $28 \cdot 38$ \\
\hline Norm for DCP intake ( $\mathrm{g} / \mathrm{d}$, last 6 weeks pre-partum)† & \multicolumn{4}{|c|}{ Increasing from 130 to 193} \\
\hline Number of lambs in the experiment & \multicolumn{2}{|c|}{20} & \multicolumn{2}{|c|}{22} \\
\hline Birth weight of lambs $(\mathrm{kg})$ & $4.68^{\mathrm{a}}$ & 0.19 & $4 \cdot 13^{\mathrm{b}}$ & 0.14 \\
\hline \multicolumn{5}{|l|}{ Number of lambs } \\
\hline Male & & & & \\
\hline Female & \multicolumn{2}{|c|}{13} & \multicolumn{2}{|c|}{10} \\
\hline Birth weight of males $(\mathrm{kg})$ & $4 \cdot 78^{\mathrm{C}}$ & 0.41 & $4 \cdot 39^{d}$ & 0.20 \\
\hline Birth weight of females $(\mathrm{kg})$ & $4.62^{\mathrm{a}}$ & 0.19 & $3 \cdot 82^{\mathrm{b}}$ & 0.15 \\
\hline
\end{tabular}

NORM, normal diet; LOW, $50 \%$ of normal diet; BCS, body condition score; DE, digestible energy; DCP, digestible crude protein.

${ }^{\mathrm{a}, \mathrm{b}}$ Least square mean values within a row with unlike superscript letters were significantly different $(P<0.05)$.

${ }^{c, d}$ Least square mean values within a row with unlike superscript letters were significantly different $(P=0.06)$.

$x, y$ Least square mean values within a row with unlike superscript letters were significantly different $(P<0.001)$

${ }^{*}$ NORM and LOW diets fulfilled 100 and $50 \%$, respectively, of daily requirements for energy during the last 6 weeks of gestation.

†NORM and LOW diets fulfilled 100 and $50 \%$, respectively, of daily requirements for protein during the last 6 weeks of gestation.

random effects; e is a $N$-dimensional vector of residuals. The random effects $\mathrm{b} \sim N(0, \Sigma)$ and $\mathrm{e} \sim N\left(0, \sigma^{2} \Lambda\right)$ are assumed to be mutually independent. Matrices $\Sigma$ and $\Lambda$ were positivedefinite matrices parameterised by a general small set of parameters, modelling dependence between observations from the same unit (lamb or sheep). For each model, the residuals were plotted against the model predicted to assess homogeneity of variance and potential influential observations $^{(39,40)}$. Normality assumptions were checked by means of quantile-quantile plots. Model reductions were done by sequentially removing the least significant factor. Data are represented as least square means with their standard errors unless otherwise stated.

The potential confounding with sex and age at slaughter is acknowledged. The organ data model included fixed effects of age (6 months and 2 years), lamb diet (CONV and HCHF), sheep diet (LOW and NORM), age at slaughter for certain parameters and their interactions. Sheep $(1, \ldots, 21)$ was included as a random effect to account for twin effect. The body proportion data were analysed separately for animals younger and older than 6 months of age. The first-order autoregressive process was dropped, but the random effect of lamb was kept, providing a compound symmetry correlation structure for observations on the same animal.

All models were incorporated in $\mathrm{R}^{(41)}$ utilising the packages nlme and multcomp for fitting the linear mixed models and multiple comparisons, respectively ${ }^{(42,43)}$.

\section{Results}

Only for very few of the parameters reported in the present study could we detect a significant interaction between

Table 3. Digestible energy (DE) and crude protein intake of the experimental lambs from birth to 6 months of age* (Least square means (LSMEAN) with their standard errors)

\begin{tabular}{|c|c|c|c|c|c|c|c|c|}
\hline & \multicolumn{2}{|c|}{ NORM-CONV } & \multicolumn{2}{|c|}{ NORM-HCHF } & \multicolumn{2}{|c|}{ LOW-CONV } & \multicolumn{2}{|c|}{ LOW-HCHF } \\
\hline & LSMEAN & SEM & LSMEAN & SEM & LSMEAN & SEM & LSMEAN & SEM \\
\hline \multicolumn{9}{|l|}{ Number of lambs } \\
\hline Male & \multicolumn{2}{|c|}{2} & \multicolumn{2}{|c|}{5} & \multicolumn{2}{|c|}{6} & \multicolumn{2}{|c|}{6} \\
\hline Female & \multicolumn{2}{|c|}{8} & \multicolumn{2}{|c|}{5} & \multicolumn{2}{|c|}{5} & \multicolumn{2}{|c|}{5} \\
\hline \multicolumn{9}{|l|}{ DE intake $(\mathrm{MJ} / \mathrm{d})$} \\
\hline $0-8$ weeks & $6 \cdot 1$ & 0.47 & $11 \cdot 0 \dagger$ & 0.78 & $5 \cdot 5$ & 0.50 & $11 \cdot 2 \dagger$ & 1.03 \\
\hline 8 weeks -6 months & $12 \cdot 8$ & 1.12 & $16 \cdot 6 \neq$ & 1.79 & $12 \cdot 5$ & 1.91 & 14.5 & 1.96 \\
\hline \multicolumn{9}{|c|}{ Digestible crude protein intake $(\mathrm{g} / \mathrm{d})$} \\
\hline $0-8$ weeks & $84 \cdot 0$ & $7 \cdot 8$ & $76 \cdot 6$ & $5 \cdot 25$ & $76 \cdot 7$ & 7.93 & $75 \cdot 7$ & $12 \cdot 2$ \\
\hline 8 weeks -6 months & $195 \cdot 0$ & $16 \cdot 7$ & $72 \cdot 0 \dagger$ & 8.79 & $191 \cdot 0$ & 28.8 & $63.3 \dagger$ & 9.01 \\
\hline
\end{tabular}

NORM, normal diet; CONV, conventional hay diet; LOW, $50 \%$ of normal diet; HCHF, high-carbohydrate-high-fat diet.

* The experimental lambs were offspring of NORM or LOW during the last 6 weeks of gestation. From $3 \mathrm{~d}$ to 6 months of age, the lambs were fed either a CONV, which was adjusted to achieve moderate growth rates, or a HCHF consisting of popped maize, dairy cream and milk replacer. The CONV lambs were additionally fed milk replacer during the first 8 weeks postpartum.

$\dagger$ There was a main effect of the postnatal diet (CONV $v$. HCHF, $P<0.001$ )

$\ddagger$ Least square mean value was significantly different from that of the CONV groups (LOW-CONV and NORM-CONV, $P<0.001$ ). 
pre- and early postnatal nutrition. Therefore, in the following paragraphs, no interactions between pre- and early postnatal nutrition were observed unless specifically stated. Likewise, no significant differential responses to prenatal and postnatal diets with age (for those parameters where this could be evaluated) were observed unless specifically stated.

\section{Birth weight of offspring, colostrum yield and mitogenic activity}

Birth weight was significantly reduced in female lambs by late gestation undernutrition and was $550 \mathrm{~g}$ lower in the LOW females than in the NORM females $(P=0.05$; Table 2$)$. It was also reduced in male lambs, but the difference did not quite reach significance $(P=0.056$; Table 2$)$.

Colostrum production was significantly lower in the LOW sheep than in the NORM sheep $(335.5$ (SEM 55.8) $v .541 \cdot 1$ (SEM 65.4) $\mathrm{ml}, P<0.05$ ). Insulin growth factor I concentration in the colostrum was unaffected by the pre-partum treatment (683 (sEm 65) v. 631 (SEM 65) ng/ml).

\section{Dietary intakes, feed preferences and respiratory quotients}

During the milk-feeding period (from day 3 to 8 weeks of age), digestible energy intake was about $100 \%$ higher in the HCHF lambs than in the CONV lambs (Table 3), for which feed intakes were adjusted weekly to achieve moderate weight gains. However, daily protein intakes were in the same range for all experimental groups during the first 8 weeks of life, where milk supplementation was given to all lambs (Table 3).

From 8 weeks (weaning of CONV lambs) to 6 months of age, the average daily intake of digestible energy was higher in the NORM-HCHF group compared with the other groups. The CONV lambs had approximately three times higher digestible crude protein intake than HCHF-fed lambs during this period (Table 3).

Interestingly, as shown in Fig. 2, the HCHF lambs exposed to the LOW-HCHF diet had an increased appetite for the highfat dairy cream $(P=0.004)$, and the first animals had already reached their maximal daily allowance by 3 weeks of age compared with 6 weeks of age for the NORM-HCHF lambs. In contrast, consumption of high-starch maize by the LOWHCHF lambs during the first 6 weeks of life was only onethird of that consumed by the NORM-HCHF lambs, and maize intake remained lowest in the LOW-HCHF lambs throughout the experimental feeding period $(P<0 \cdot 001)$

In 6-month-old lambs, the HCHF diet as expected changed substrate oxidation in the direction of a more lipid-based metabolism as evidenced by lower respiratory quotient values (0.82 (SEM 0.038)) compared with animals fed the CONV diet (0.91 (SEM 0.034)) $(P=0.004)$.

\section{Body weight and body proportions}

Growth rates of about $225 \mathrm{~g} / \mathrm{d}$, being close to what was planned (see above), were achieved in both groups of
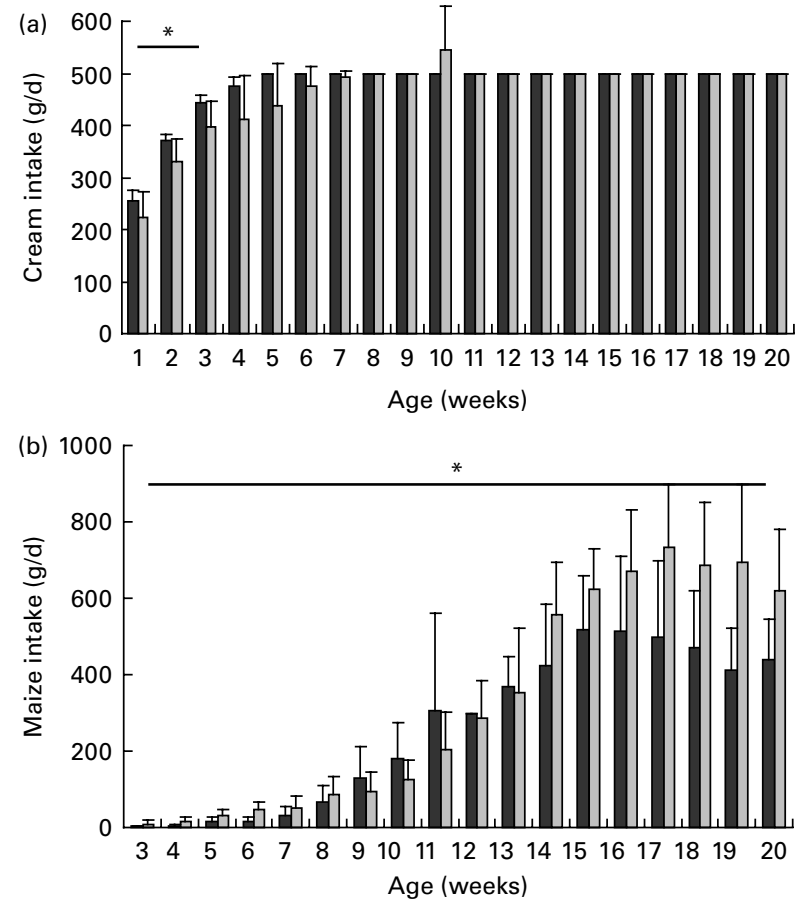

Fig. 2. Daily dietary intake of (a) fat-rich cream and (b) starch-rich maize in the high-carbohydrate-high-fat diet (HCHF) lambs during the early postnata experimental feeding period. Maximum daily allowances of cream and popped maize were 0.5 litres $/ \mathrm{d}$ and $1.0 \mathrm{~kg} / \mathrm{d}$, respectively. Values are least square means, with their standard errors represented by vertical bars. For cream, statistical differences in intakes (marked with *) could only be evaluated for the period from $3 \mathrm{~d}$ to 3 weeks of age, where the first animals reached their maximum daily allowance for cream. NORM, normal diet fulfilling norms for energy and protein; LOW, $50 \%$ of a normal diet; CONV, conventional diet. The LOW-HCHF ( $\square$ ) lambs had a higher cream intake than the NORM-HCHF $(\square)$ lambs $(P=0.004)$ during these first 3 weeks. Maize intake was significantly higher $(P<0.001)$ in the NORM-HCHF lambs than in the LOW-HCHF lambs throughout the experimental feeding period, except from 9 to 13 weeks of age. NORM-CONV $(n 10)$, NORM-HCHF $(n$ 9), LOWCONV (n 10) and LOW-HCHF ( $n$ 9).

CONV-fed lambs during the first 6 months of life through the weekly adjustment of their dietary provision.

The prenatal diet had no effect on weight gain in early postnatal life from $3 \mathrm{~d}$ to 6 months of age in any of the lambs studied (Fig. 3). The HCHF lambs increased their body weights with almost $50 \%$ more compared with the CONV lambs $(P<0.001 ;$ Fig. 3$)$, and also had larger girth circumferences $(P=0.004)$ at 8 weeks of age $(72 \cdot 1$ (SEM 1.4) v. 61.1 (SEM $1.3) \mathrm{cm}$ ) and 6 months of age $(84.4($ SEM 1.5) v. $77 \cdot 4$ (SEM $1.4) \mathrm{cm}$ ). Crown-rump length and height over withers were not affected by the prenatal $(P=0 \cdot 28$ and $0 \cdot 16$, respectively) or postnatal $(P=0.09$ and $0 \cdot 16$, respectively) treatments during the early growth period.

After the change to a moderate feeding level at 6 months of age (at which point all sheep remaining in the experiment were females), the LOW-HCHF females lost about $10 \%$ of their body weight over the following 6 months, the NORMHCHF females maintained their body weights, whereas the two CONV groups continued to grow (Fig. 4). From 1 to 2 years of age, the NORM females increased their body weights more than the LOW females $(P=0.002)$, and at 2 years of age, 


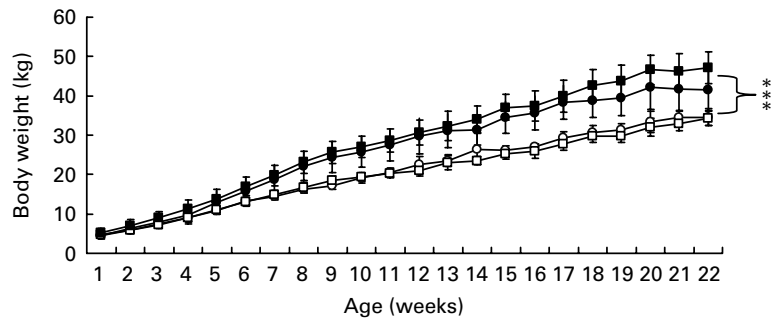

Fig. 3. Influence of pre- and postnatal nutrition exposures on growth patterns of lambs (males and females) from birth to 22 weeks of age. NORM, normal diet fulfilling norms for energy and protein; LOW, $50 \%$ of a normal diet; CONV, conventional diet; HCHF, high-carbohydrate-high-fat diet. NORMCONV ( $\square, n$ 10), NORM-HCHF ( $\square, n 9)$, LOW-CONV $(O, n 10)$ and LOW$\operatorname{HCHF}(\bullet, n 9) .{ }^{* \star \star} P<0.001$.

the NORM-HCHF females had higher body weights than the LOW-CONV sheep $(P=0 \cdot 04)$ and tended to have higher body weights than the LOW-HCHF sheep $(P=0 \cdot 07)$. A longterm effect of prenatal undernutrition (LOW) was observed on body proportions, where the LOW females had smaller girth circumferences $(88.5$ (SEM 1.8) $v .97 .8 \quad(1.7) \mathrm{cm}$, $P<0.001)$ than the NORM females at 2 years of age.

\section{Organ development and fat deposition patterns in male lambs and in adult females}

Due to the subdivision of sexes at the two slaughter times at 6 months and 2 years of age, it is unfortunately not possible to distinguish sex and age effects when evaluating organ and fat depot weights.

In the 6-month-old males, the HCHF diet compared with the CONV diet significantly increased the gross weight of renal fat, abdominal fat and the thickness of the subcutaneous fat layer and the significances were maintained also when correcting for differences in body weight (Table 4). In contrast, kidney weight was reduced by close to $33 \%$ in the HCHF lambs compared with CONV lambs at 6 months of age, even after correction for body weight. The only prenatal (LOW) effects, which remained after correcting for differences in body weights, were reduced adrenal glands (0.72 (SEM 0.05) v. 0.64 (SEM $0.06) \%$ of body weight; $P=0.019)$ compared with the NORM animals, and this was seen in both the males slaughtered at 6 months of age and in adult females after 1.5 years of dietary correction. The subcutaneous back fat layer was also thinner in the LOW animals compared with NORM animals (both sexes at each their age; 2.83 (SEM 0.85) v. 4.2 (SEM 0.82) mm; $P=0 \cdot 01$ ). At 2 years of age, the extensive body fat deposition in the HCHF sheep was no longer apparent, and at slaughter, no differences (except for biceps femoris) could be demonstrated between the HCHF and CONV females (Table 4). The depressive effect of the postnatal HCHF diet on kidney weights, which was seen in the 6-month-old-males, was not observed in the 2-year-old females (Table 4).

The HCHF males slaughtered at 6 months of age had developed liver that was obviously fatty, as indicated by a very pale colour compared with the dark purple colour of CONV liver (Fig. 5(c)). In addition, the HCHF males had pericardial fat infiltration and we observed widespread and extensive fat deposition (Fig. 5(b) and (d)), which was in sharp contrast to the slender CONV males.

CT scans of the 6-month-old living females revealed very high fat:lean ratios of 0.60 in the LOW-HCHF females and 0.70 in the NORM-HCHF females, corresponding to fat contents in soft tissues of 38 and $41 \%$, respectively (Fig. 6(a)), and they had substantially higher visceral:subcutaneous fat ratios than the CONV females $(P<0 \cdot 001 ;$ Fig. 6(b)). It was noteworthy that the female lambs, which had been undernourished in late gestation (LOW), had particularly high visceral:subcutaneous fat ratios when exposed to a mismatched high-fat diet in early postnatal life $(P=0.0084)$, and this was associated with a reduced fat deposition in subcutaneous adipose tissue (thinner subcutaneous fat layer in the LOW females compared with the NORM females) (2.83 (SEM 0.82) v. $4 \cdot 21($ SEM $0 \cdot 85) \mathrm{mm}, P=0 \cdot 012)$.

At 2 years of age ( 1.5 year after diet conversion), the high fat:lean ratios previously observed in the HCHF females were no longer evident and the only significant difference observed was a lower fat:lean ratio in the LOW-CONV females compared with the NORM-HCHF females $(P<0 \cdot 05$; Fig. 6(a)).

\section{Discussion}

The present study presents the new Copenhagen sheep model, in which obesity (fat content in soft tissues of $>38 \%$ ) and altered lipid deposition patterns can be successfully induced in lambs with a special postnatal feeding regimen. Due to circumstances beyond our control, we were unable to subdivide ewes and rams into separate flocks when the differential feeding period and individual housing came to an end around puberty. Since all males were slaughtered at 6 months of age, sex and age effects were obviously confounded for fat and organ weights in the present study. However, the effects of pre- and postnatal nutrition combinations on early-life feed preferences, growth and development in body proportions, and fat deposition patterns

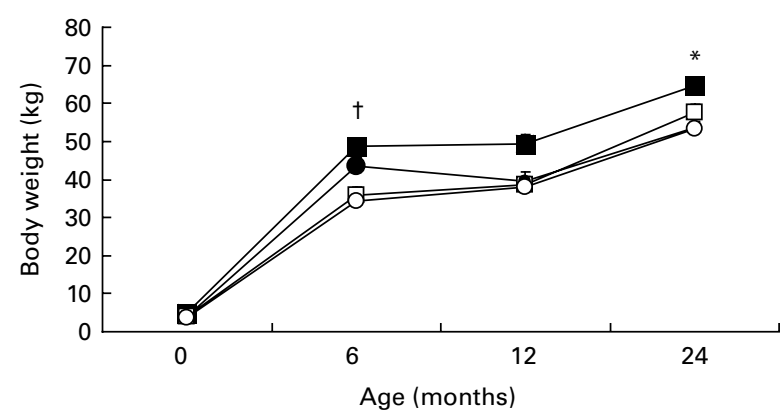

Fig. 4. Body weights of female experimental animals from birth to young adulthood (2 years of age). NORM, normal diet fulfilling norms for energy and protein; LOW, $50 \%$ of a normal diet; CONV, conventional diet; HCHF, high-carbohydrate-high-fat diet. *There was a significant difference $(P<0.05)$ between the LOW-CONV and NORM-HCHF groups. †There was a significant effect for the postnatal diet $(P<0.05)$ : see legend to Fig. 1 . NORM-CONV ( $\square, n 4)$, NORM-HCHF $(\square, n 4)$, LOW-CONV $(O, n 5)$ and LOW-HCHF $(\bullet, n$ 4). 
Table 4. Slaughter organ weights (in $\mathrm{g}$ and as a percentage of total body weight) of the experimental animals at 6 months (males and three females) and 2 years (females) of age ${ }^{*}$

(Least square means (LSMEAN) with their standard errors)

\begin{tabular}{|c|c|c|c|c|c|c|c|c|c|c|}
\hline \multirow{3}{*}{$\begin{array}{l}\text { Oragan }(\mathrm{g}) \text { and } \% \text { of } \\
\text { total body weight }\end{array}$} & \multicolumn{5}{|c|}{6 months } & \multicolumn{5}{|c|}{2 years } \\
\hline & \multicolumn{2}{|c|}{ CONV } & \multicolumn{2}{|c|}{$\mathrm{HCHF}$} & \multirow[b]{2}{*}{$P$} & \multicolumn{2}{|c|}{ CONV } & \multicolumn{2}{|c|}{$\mathrm{HCHF}$} & \multirow[b]{2}{*}{$P$} \\
\hline & LSMEAN & SEM & LSMEAN & SEM & & LSMEAN & SEM & LSMEAN & SEM & \\
\hline \multicolumn{11}{|l|}{ Kidney } \\
\hline g & 129 & 4.5 & 99 & 5 & 0.002 & 110 & 4.9 & 108 & $5 \cdot 2$ & 0.80 \\
\hline$\%$ & 0.32 & 0.01 & 0.21 & 0.01 & $<0.001$ & $0 \cdot 21$ & 0.01 & 0.19 & 0.01 & 0.25 \\
\hline \multicolumn{11}{|l|}{ Liver } \\
\hline g & 577 & 17 & 607 & 18 & 0.29 & 467 & 18 & 475 & 19 & 0.78 \\
\hline$\%$ & 1.45 & 0.05 & 1.28 & 0.05 & 0.11 & 0.87 & 0.04 & 0.83 & 0.04 & 0.45 \\
\hline \multicolumn{11}{|l|}{ Heart } \\
\hline $\mathrm{g}$ & 161 & 11 & 203 & 12 & 0.03 & 207 & 12 & 235 & 13 & $0 \cdot 12$ \\
\hline$\%$ & 0.41 & 0.02 & 0.44 & 0.02 & 0.24 & 0.39 & 0.02 & 0.40 & 0.02 & 0.65 \\
\hline \multicolumn{11}{|l|}{ Thyroid } \\
\hline g & $4 \cdot 12$ & 0.49 & 2.92 & 0.51 & 0.71 & 3.04 & 0.58 & 3.73 & 0.63 & 0.46 \\
\hline$\%$ & 0.010 & 0.0013 & 0.0061 & 0.0015 & 0.3 & 0.0057 & 0.0016 & 0.0068 & 0.0018 & 0.67 \\
\hline \multicolumn{11}{|l|}{ Adrenals } \\
\hline g & 2.75 & 0.20 & $2 \cdot 49$ & 0.21 & 0.99 & 3.97 & 0.22 & $4 \cdot 27$ & 0.22 & 0.35 \\
\hline$\%$ & 0.0069 & 0.00049 & 0.0052 & 0.00057 & 0.26 & 0.0075 & 0.00052 & 0.0077 & 0.00055 & 0.77 \\
\hline \multicolumn{11}{|l|}{ Longissimus $†$} \\
\hline $\mathrm{g}$ & 420 & 35 & 581 & 37 & 0.03 & 649 & 39 & 657 & 41 & 0.90 \\
\hline$\%$ & 1.05 & 0.05 & 1.27 & 0.06 & 0.13 & $1 \cdot 20$ & 0.05 & $1 \cdot 15$ & 0.06 & 0.54 \\
\hline \multicolumn{11}{|l|}{ Biceps $\ddagger$} \\
\hline g & 275 & 37 & 290 & 39 & $0 \cdot 10$ & 336 & 39 & 450 & 41 & 0.05 \\
\hline$\%$ & 0.69 & 0.09 & 0.63 & 0.09 & 0.46 & 0.63 & 0.09 & 0.83 & 0.10 & 0.15 \\
\hline \multicolumn{11}{|l|}{ Renal fat } \\
\hline g & 123 & 77 & 1129 & 81 & $<0.001$ & 570 & 82 & 432 & 93 & 0.28 \\
\hline$\%$ & 0.31 & 0.11 & 2.42 & 0.13 & $<0.001$ & $1 \cdot 0$ & 0.12 & 0.72 & 0.13 & 0.13 \\
\hline \multicolumn{11}{|l|}{ Abdominal fat } \\
\hline g & 278 & 238 & 1803 & 246 & $<0.001$ & 1149 & 252 & 1548 & 266 & 0.29 \\
\hline$\%$ & 0.70 & 0.31 & 3.88 & 0.33 & $<0.001$ & $2 \cdot 07$ & 0.34 & $2 \cdot 47$ & 0.36 & 0.42 \\
\hline Subcutaneous fat $(\mathrm{mm}) \S$ & 1.60 & 0.74 & $13 \cdot 17$ & 0.96 & $<0.001$ & 0.22 & 0.79 & 0.38 & 0.83 & 0.90 \\
\hline
\end{tabular}

CONV, conventional diet; HCHF, high-carbohydrate-high-fat diet.

* The animals were fed a moderate CONV or HCHF from $3 \mathrm{~d}$ to 6 months of age.

† Muscularis longissimus dorsi.

$\ddagger$ Biceps femoris.

$\S$ Subcutaneous back fat thickness measured above the longissimus dorsi muscle at the last rib.

(visceral $v$. subcutaneous) could be evaluated in both male and female animals until 6 months of age. We could also determine the impacts of these pre- and postnatal dietary exposures on the development of individual organs in male animals at 6 months of age (young animals) when they were killed. Furthermore, we could demonstrate how a long period of dietary correction affected fat deposition patterns in young adult, female sheep with different histories of pre- and postnatal nutrition, since fat deposition patterns were characterised in these females by CT scanning at both 6 and 24 months of age. It should be remembered that we detected only a very few significant interactive effects of pre- and postnatal nutrition for the parameters reported here, and we are only addressing issues relating to interactions in the discussion when significant effects were detected. The data presented here demonstrate the potential usefulness of sheep as an experimental animal model, even for postnatal dietary interventions, and notwithstanding the characteristic features of the ruminant digestive system. It was one of the main objectives of the study to establish such a new large animal model, which is comparable to humans in terms of gestational period, number of offspring, birth weight and maturity at birth.

\section{Late gestational nutrition influences food preferences in early postnatal life}

Young lambs that were undernourished during late gestation (LOW) preferred to eat a fat- and energy-dense diet (dairy cream) and reached the predefined daily limit for dairy cream intake 3 weeks earlier than those born to NORM-fed mothers who preferred to eat more of the less energy-dense and starch-rich popped maize. In a human study investigating food preferences in offspring born to undernourished mothers during the Dutch hunger famine, it has been shown that such offspring preferred more fatty foods in adult life, findings which are also supported in a rat model of $\operatorname{IUGR}^{(44,45)}$.

To the best of our knowledge, we are the first to conduct such an extreme dietary manipulation in a ruminant animal (sheep) in order to mimic a high-carbohydrate-high-fat feeding regimen as might be found in monogastrics. It is very interesting that our dietary manipulation revealed the same changes in food preferences in the young ruminant in response to prenatal undernutrition that have been reported in other monogastric species such as humans ${ }^{(45)}$. Although our data cannot show whether the increased taste for highfat feeds persists into adulthood in the LOW sheep, and 
(a)

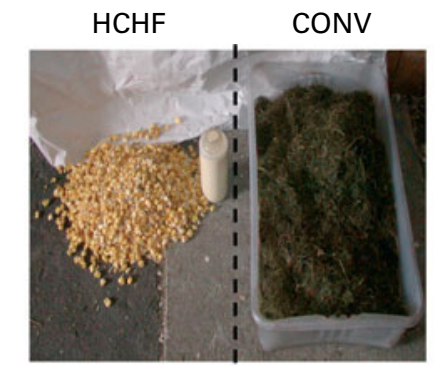

(b)

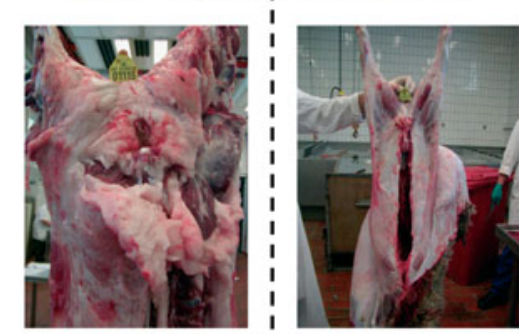

(c)

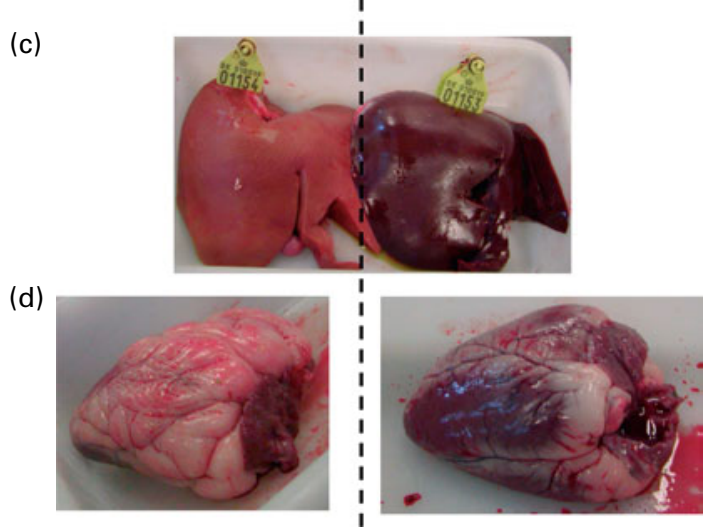

Fig. 5. Impact of a postnatal high-carbohydrate-high-fat diet (HCHF; pictures to the left-hand side of dashed line) or a moderate conventional diet (CONV; pictures to the right-hand side) on carcass characteristics in lambs. (a) Representative daily feed ration offered to the HCHF or CONV lambs, (b) phenotype and carcass characteristics in animals at 6 months of age (pictures are representative for male lambs from the HCHF and CONV groups, respectively), (c) representative HCHF lamb liver demonstrating the extensive fat infiltration (note the pale colour) compared with the normal CONV liver and (d) HCHF heart with clearly visible pericardial infiltration compared with a normal CONV heart.

although the typical diet for a ruminant during evolution was never rich in fat, this points towards a mechanism whereby prenatal undernutrition can programme food preference for a high-fat diet.

\section{Weight gain during the early growth phase is determined by postnatal nutrition}

In several other rat and sheep studies, where prenatal undernutrition has been combined with postnatal ad libitum feeding, observations such as hyperphagia, catch-up growth and accelerated weight gains have been reported in animals exposed to prenatal undernutrition compared with animals that were adequately nourished prenatally ${ }^{(46-48)}$. However, the LOW-HCHF lambs in the present study did not ingest more energy or gain more weight than the NORM-HCHF animals. This might be related to the time window of intervention during gestation, which in the present study was in the third trimester. In terms of development and maturation, this corresponds more to the lactation period in rats. However, it may also relate to our imposed limitation on daily dairy cream intake by the HCHF lambs, thus giving them ad libitum access only to maize. The cream intake limit of 0.5 litres/d was reached within the first 3-5 weeks of age in the LOW lambs compared with 6-8 weeks of age in the NORM lambs. As described above, the LOW-HCHF lambs found cream more palatable than maize and, if we had offered the cream mix ad libitum, they could possibly have continued to increase intake, and consequently gained more weight and develop larger adipose tissue stores than the NORMHCHF lambs. As for the CONV lambs, the daily feed provision
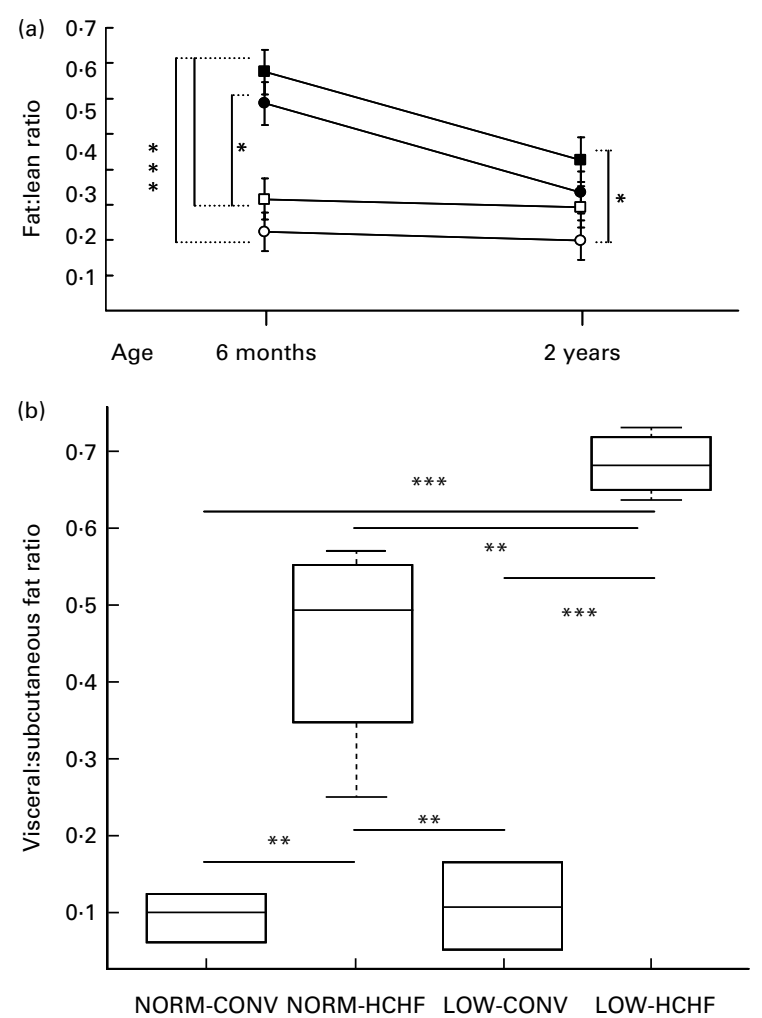

Fig. 6. Fat deposition patterns in female experimental animals measured by computer tomography (CT) scanning in the tracheal region. (a) Fat:lean ratios at 6 months and 2 years of age. Note that ratio of 1.0 and 0.6 are equivalent to a fat percentage in soft tissues of 50 and $38 \%$, respectively. In CT scans from 2-year-old animals, the forestomachs were large and full of ingesta, and could not be distinguished from fat and lean tissues. Data from 2 years of age were therefore derived from a single transverse slice containing the tracheal bifurcation. For three of the sheep (not from the same dietary group) scanned at 2 years of age, fat quantities were below the threshold of detectability. Fat:lean ratios in these animals were set to the lowest detectable fat:lean ratio $(11.7 \%)$. This may have led to a slight overestimation of adiposity for these three individuals. *There was a significant effect for the postnatal diet $(P<0.05)$. (b) Visceral:subcutaneous fat ratios in females at 6 months of age by the end of the postnatal period with differential feedings. Values are least square means, with standard errors represented by vertical bars. Mean values were significantly different between the groups: ${ }^{\star} P<0.05$, ${ }^{\star \star} P<0.01$ and ${ }^{\star \star *} P<0.001$. NORM, normal diet fulfilling norms for energy and protein; LOW, $50 \%$ of a normal diet; CONV, conventional diet; HCHF, high-carbohydrate-high-fat diet. NORM-CONV $(\square, n$ 4), NORM-HCHF ( $\square, n 4)$, LOW-CONV $(O, n 5)$ and LOW-HCHF $(\bullet, n$ ) (see legend to Fig. 1).

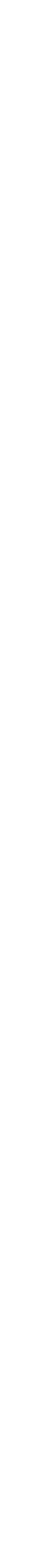


was continuously adjusted to ensure a moderate and fixed daily weight gain during the first 6 months of life, irrespective of the prenatal nutrition exposures, which we successfully achieved. Any capacity for catch-up growth in the LOWCONV lambs compared with the NORM-CONV lambs could therefore not be expressed during the early postnatal growth phase. However, after the differential feeding period, where the females were allowed to eat ad libitum of the normal low-fat, grass-based diet, we did not see any indications of long-term prenatal programming of weight gain. In contrast and to our surprise, we found that the LOW lambs and sheep had reduced subcutaneous fat and smaller girth circumferences compared with the NORM sheep. Thus, and in agreement with Bellinger et al. ${ }^{(49)}$, prenatal undernutrition does not seem to be a risk factor for increased adiposity per se, unless the offspring are challenged by a high-fat diet after birth.

\section{Effects of early postnatal overnutrition on visceral and} ectopic fat deposition can (in females) be reversed by dietary correction later in life

Due to their higher dietary energy intake, the HCHF lambs had higher growth rates and achieved larger body size and weight at 6 months of age than the CONV lambs. This was associated with a proportional increase in the development of different body tissues and organs, since virtually all postnatal dietary effects on organ weights disappeared upon correction for body weight. Adipose tissue was a notable exception. The HCHF lambs clearly became obese with fat percentages in lean tissues exceeding 38\% in female animals, and this substantial increase in fat deposition was observed in all of the three adipose tissues investigated, both from CT scans of females and males at slaughter. The development of obesity was associated with a dramatic increase in the visceral:subcutaneous fat ratio in young females, and widespread ectopic fat deposition was clearly visible in the slaughtered HCHF male lambs. This is interesting, since it has been demonstrated in human subjects and in rodent models that visceral adiposity can predispose for development of the metabolic syndrome, whereas subcutaneous fat is considered a more 'healthy' fat ${ }^{(17,49,50)}$. When the obese HCHF female lambs were transferred to a moderate diet for 1.5 years, body fat content was completely normalised, and in adult sheep, the fat distribution pattern in the adult HCHF sheep did not differ from that of the CONV sheep (without a previous history of obesity).

The HCHF diet had a negative impact on only one organ, the kidney, whose weight (when corrected for body weight) was reduced by a dramatic $33 \%$ in the HCHF male lambs compared with the CONV male lambs. The low protein level in the HCHF diet may have played an important role in this context, since it has been shown in another sheep study that an adequate protein supply is important to sustain kidney growth and development ${ }^{(51)}$. However, the limited protein supply to the HCHF lambs did not interfere with skeletal muscle or longitudinal growth. In the HCHF lambs, the higher energy intake must therefore have compensated for a low dietary protein intake to improve protein utilisation, which is a well-known phenomenon $^{(52)}$, and in this way, normal skeletal and longitudinal growth could be sustained, and, in fact, quantitatively increased in the HCHF lambs compared with the CONV lambs. In the adult female sheep, there were no indications that kidney weight was influenced by the nutritional history (HCHF or CONV) in early postnatal life. Our data do not allow us to evaluate whether the dietary correction and higher protein intake after 6 months of age could have stimulated a compensatory growth of the kidneys in the HCHF females, or whether the kidney response to postnatal diets differs between males and females.

\section{LOW diet might interfere with subcutaneous fat expandability and increases the disposition for visceral adiposity upon exposure to a high-fat postnatal diet in postnatal life}

The present study contributes to the growing body of experimental and observational evidence in animals and human subjects that prenatal life events can be important in setting fat mass and fat distribution patterns later in life ${ }^{(53)}$. Lambs subjected to the LOW diet had a higher disposition for visceral fat deposition when exposed to a high-fat diet very early in postnatal life. Interestingly, this was associated with reduced subcutaneous adipose tissue thickness, as observed in both male and female lambs, resulting in increased visceral:subcutaneous fat ratios. This impact of the LOW diet on subcutaneous fat was still evident in the adult females irrespective of their postnatal nutritional history, suggesting that late gestational undernutrition may have differential programming effects in different adipose tissues. In subcutaneous adipose tissue, the programming outcome of the LOW diet might be a limited capacity for expansion in response to overnutrition in postnatal life. The thinner subcutaneous fat layer observed in the LOW offspring supports findings from other species, in which IUGR has been shown to interfere with the development and size of subcutaneous adipose tissue in postnatal life ${ }^{(11,49)}$. The mechanisms whereby prenatal undernutrition can interfere with adipocyte development, and in a tissuespecific manner, are not known. It will be very important to investigate such mechanisms in future studies, as they may contribute to explain how adverse intra-uterine conditions can predispose for development of visceral adiposity and the metabolic syndrome in later life. In this context, it is very interesting that subcutaneous adipose tissue has been suggested to play a specific role in the development of visceral adiposity and ectopic fat deposition ${ }^{(54)}$. Reduced fat accumulation capacity in subcutaneous adipose tissue can cause a nutrient overflow when dietary intake is abundant, resulting in visceral fat deposition. This is important when one considers that the death of adipocytes is closely related to their growth up to the critical death size, and this death size is smaller in the visceral adipocyte than in the subcutaneous adipocyte $^{(54)}$. This probably accounts for the greater morbidity related to visceral fat ${ }^{(54)}$ and the subsequent association with ectopic fat deposition.

Thus, the outcomes of prenatal exposure to a LOW plane of nutrition on fat deposition patterns and subcutaneous fat 
thickness could not be reversed in female animals by dietary correction later in life, in contrast to the effects of postnatal dietary exposures introduced as early as $3 \mathrm{~d}$ after birth. This points to birth as a critical time point in relation to when long-term programming of body functions can be induced.

We also found, in agreement with other studies, that prenatal undernutrition increases the size of the adrenal glands, supporting the theory that the hypothalamic-pituitaryadrenal axis is important for postnatal adaptations in individuals subjected to prenatal undernutrition ${ }^{(55,56)}$. In human studies, low birth weight has been associated with hypothalamic-pituitary-adrenal axis overactivity, insulin resistance and the metabolic syndrome, and overactivity of the hypothalamic-pituitary-adrenal axis has in turn been associated with visceral obesity and development of the metabolic syndrome ${ }^{(57,58)}$. The increased adrenal weight relative to total body weight observed in our LOW offspring could be indicative of hypothalamic-pituitary-adrenal axis hyperactivity, and other animal studies have indeed revealed a strong prenatal programming effect on this axis, which becomes increasingly manifested with age ${ }^{(55,56)}$. However, it remains to be established whether changes in this or other endocrine systems are implicated in the programming of adipose tissue deposition, function and/or expandability.

\section{Conclusion}

We have demonstrated that our Copenhagen sheep model has the potential to expose the underlying mechanisms by which pre- and early postnatal nutrition interact to modify body functions and development in a manner that can predispose for obesity and the metabolic syndrome later in life. The present study has shown that adolescent lambs exposed to a LOW plane of nutrition prenatally had a higher disposition for development of visceral adiposity when exposed to a highfat diet in early postnatal life compared with lambs that were adequately nourished in fetal life. Increased appetite for high-fat over carbohydrate-rich foods observed in the LOW lambs may exacerbate this visceral adiposity risk. The association between an increased disposition for visceral adiposity and a reduced fat accumulation capacity in subcutaneous adipose tissue in lambs of both sexes and in adult female sheep (irrespective of their postnatal dietary history) suggests that subcutaneous adipose tissue is a target organ for fetal programming. Expandability of subcutaneous adipose tissue can thus be a key factor controlling the apportionment of a nutrient overflow, directing it towards visceral and ectopic fat deposition, which in humans is known to precede the development of the metabolic syndrome and type 2 diabetes. The effects of postnatal dietary exposures, introduced right after birth, on fat deposition patterns appeared to be almost completely reversible after dietary correction in the adult females studied, in contrast to the effects of prenatal exposures. This suggests that birth is a critical time point in relation to adverse long-term programming. The sheep model can thus be particularly relevant when fetal exposures in the third trimester are the focus of interest.

\section{Acknowledgements}

This study was part of the research programme of the Centre for Fetal Programming (CFP), Denmark, and was supported by the Danish Council for Strategic Research (grants 09059921 and 09 067124). The authors would like to acknowledge D. S. Jensen, R. Jensen, A. Ali, M. Stubgaard and L. E. Carlsen for their valuable technical assistance. We also wish to express our gratitude to the following people for expert help with handling of the experimental animals, slaughtering and samplings: the experimental farm staff at the Faculty of Life Sciences, University of Copenhagen, Denmark; PhD students A. Kiani and A. N. Rasmussen; animal science students A. C. F. Støy, M. B. Petersen, H. F. Hedegaard, M. Kjærgaard, K. F. Dahlbach, M. P. Jensen, B. C. Jensen and S. R. Thomasen. Thanks are also due to M. Birtwistle, University of Nottingham, Nottingham, UK, for proofreading of the manuscript. M. O. N. designed and developed the sheep model and together with A. H. K. wrote the manuscript. M. O. N., A. H. K., M. P. T., S. H. and V. G. C. were the main persons responsible for the experimental planning, and they took part in all experimental work with the animals and in the evaluation of results. B. Q., W. J. and S. C. participated in parts of the experimental work and slaughtering of the animals. A. C. was in charge of the open-air calorimetric measurements. L. J., E. S. and F. J. M. were responsible for the evaluation of the CT scannings. K. S. and S. P. conducted the mitogenic activity measurements with the mammary epithelial cell line. A. B. S. performed all the statistical analyses. The authors declare that there are no conflicts of interest.

\section{References}

1. Verkauskiene R, Albertsson WK \& Niklasson A (2002) Variation in size at birth in infants born small for gestational age in Lithuania. Acta Paediatr 91, 329-334.

2. Mahajan SD, Aalinkeel R, Singh S, et al. (2006) Endocrine regulation in asymmetric intrauterine fetal growth retardation. J Matern Fetal Neonatal Med 19, 615-623.

3. Forsen T, Eriksson J, Tuomilehto J, et al. (2000) The fetal and childhood growth of persons who develop type 2 diabetes. Ann Intern Med 133, 176-182.

4. Curhan GC, Willett WC, Rimm EB, et al. (1996) Birth weight and adult hypertension, diabetes mellitus, and obesity in US men. Circulation 94, 3246-3250.

5. Phillips DIW, Goulden P, Syddall HE, et al. (2005) Fetal and infant growth and glucose tolerance in the Hertfordshire Cohort Study. Diabetes 54, S145-S150.

6. Hales CN \& Barker DJ (1992) Type 2 (non-insulin-dependent) diabetes mellitus: the thrifty phenotype hypothesis. Diabetologia 35, 595-601.

7. Hales CN \& Barker DJ (2001) The thrifty phenotype hypothesis. Br Med Bull 60, 5-20.

8. Simmons RA, Gounis AS, Bangalore SA, et al. (1992) Intrauterine growth retardation: fetal glucose transport is diminished in lung but spared in brain. Pediatr Res 31, 59-63.

9. Kind KL, Roberts CT, Sohlstrom AI, et al. (2005) Chronic maternal feed restriction impairs growth but increases adiposity of the fetal guinea pig. Am J Physiol Reg Integr Comp Physiol 288, R119-R126.

10. Meas T, Deghmoun S, Armoogum P, et al. (2008) Consequences of being born small for gestational age on body 
composition: an 8-year follow-up study. J Clin Endocrinol Metab 93, 3804-3809.

11. Padoan A, Rigano S, Ferrazzi E, et al. (2004) Differences in fat and lean mass proportions in normal and growthrestricted fetuses. Am J Obstet Gynecol 191, 1459-1464.

12. Yajnik CS, Fall CH, Coyaji KJ, et al. (2003) Neonatal anthropometry: the thin-fat Indian baby. The Pune Maternal Nutrition Study. Int J Obes Relat Metab Disord 27, 173-180.

13. Kulkarni ML, Mythri HP \& Kulkarni AM (2009) 'Thinfat' phenotype in newborns. Indian J Pediatr 76, 369-373.

14. Ibanez L, Lopez-Bermejo A, Suarez L, et al. (2008) Visceral adiposity without overweight in children born small for gestational age. J Clin Endocrinol Metab 93, 2079-2083.

15. Joss-Moore LA, Wang Y, Campbell MS, et al. (2010) Uteroplacental insufficiency increases visceral adiposity and visceral adipose PPARgamma2 expression in male rat offspring prior to the onset of obesity. Early Hum Dev 86, 179-185.

16. De Blasio MJ, Gatford KL, Robinson JS, et al. (2007) Placental restriction of fetal growth reduces size at birth and alters postnatal growth, feeding activity, and adiposity in the young lamb. Am J Physiol Reg Integr Comp Physiol 292, 875-886.

17. Gallagher D, Kelley DE, Yim JE, et al. (2009) Adipose tissue distribution is different in type 2 diabetes. Am J Clin Nutr 89, 807-814.

18. Karaolis-Danckert N, Buyken AE, Bolzenius K, et al. (2006) Rapid growth among term children whose birth weight was appropriate for gestational age has a longer lasting effect on body fat percentage than on body mass index. Am J Clin Nutr 84, 1449-1455.

19. Srinivasan M, Mitrani P, Sadhanandan G, et al. (2008) A highcarbohydrate diet in the immediate postnatal life of rats induces adaptations predisposing to adult-onset obesity. J Endocrinol 197, 565-574.

20. Morris MJ, Velkoska E \& Cole TJ (2005) Central and peripheral contributions to obesity-associated hypertension: impact of early overnourishment. Exp Physiol 90, 697-702.

21. Desai M, Babu J \& Ross MG (2007) Programmed metabolic syndrome: prenatal undernutrition and postweaning overnutrition. Am J Physiol Reg Integr Comp Physiol 293, 2306-2314.

22. McMillen IC, Adam CL \& Mühlhäusler BS (2005) Early origins of obesity: programming the appetite regulatory system. J Physiol 565, 9-17.

23. Erhuma A, Bellinger L, Langley-Evans SC, et al. (2007) Prenatal exposure to undernutrition and programming of responses to high-fat feeding in the rat. Br J Nutr $\mathbf{9 8}$, 517-524.

24. Romijn HJ, Hofman MA \& Gramsbergen A (1991) At what age is the developing cerebral cortex of the rat comparable to that of the full-term newborn human baby? Early Hum Dev 26, 61-67.

25. Greenwood PL, Hunt AS, Hermanson JW, et al. (2000) Effects of birth weight and postnatal nutrition on neonatal sheep: II. Skeletal muscle growth and development. J Anim Sci $\mathbf{7 8}$, 50-61.

26. Limesand SW, Jensen J, Hutton JC, et al. (2005) Diminished beta-cell replication contributes to reduced beta-cell mass in fetal sheep with intrauterine growth restriction. Am J Physiol Reg Integr Comp Physiol 288, 1297-1305.

27. Mühlhäusler BS, McMillen IC, Rouzaud G, et al. (2004) Appetite regulatory neuropeptides are expressed in the sheep hypothalamus before birth. J Neuroendocrinol 16, 502-507.

28. National Research Council (2007) Nutrient Requirements of Small Ruminants, Animal Nutrition Series. Washington, DC: The National Academic Press.
29. Nishida Y, Takahashi Y, Oda K, et al. (1999) The effect of reflex closure of the esophageal groove on bioavailability of oral sulfamethoxazole-trimethoprim in ruminating calves. J Vet Med Sci 58, 397-400.

30. Spanski NA, Drackley JK, Davis CL, et al. (1997) Utilization of supplemental triglycerides or free fatty acids by calves from 4 to 10 weeks of age. J Dairy Sci $\mathbf{8 0}, 573-585$.

31. Mills JAN, France J \& Dijkstra J (1999) A review of starch digestion in the lactating dairy cow and proposals for a mechanistic model: 2. Postruminal starch digestion and small intestinal glucose absorption. J Anim Feed Sci 8, 451-481.

32. Mills JAN, France J \& Dijkstra J (1999) A review of starch digestion in lactating dairy cow and proposals for a mechanistic model: 1. Dietary starch characterisation and ruminal starch digestion. J Anim Feed Sci 8, 291-340.

33. Chwalibog A, Tauson AH \& Thorbek G (2004) Energy metabolism and substrate oxidation in pigs during feeding, starvation and re-feeding. J Anim Physiol Anim Nutr 88, 101-112.

34. McEvoy FJ, Madsen MT, Strathe AB, et al. (2008) Hounsfield unit dynamics of adipose tissue and non-adipose soft tissues in growing pigs. Res Vet Sci $\mathbf{8 4}, 300-304$.

35. McEvoy FJ (2007) An application of image processing techniques in computed tomography image analysis. Vet Radiol Ultrasound 48, 528-534.

36. Vestergaard M, Purup S, Frystyk J, et al. (2003) Effects of growth hormone and feeding level on endocrine measurements, hormone receptors, muscle growth and performance of prepubertal heifers. J Anim Sci 81, 2189-2198.

37. Purup S, Jensen SK \& Sejrsen K (2001) Differential effects of retinoids on proliferation of bovine mammary epithelial cells in collagen gel culture. J Dairy Res 68, 157-164.

38. Sejrsen K, Pedersen PO, Vestergaard M, et al. (2001) Biological activity of bovine milk. Contribution of IGF-1 and IGF binding proteins. Livest Prod Sci 70, 79-85.

39. Pinheiro J, Bates DM, DebRoy S, et al. (2007) Linear and nonlinear mixed effects models. R package version 3.1-83.

40. Pinheiro J \& Bates DM (2000) Mixed Effects Models in S and $S$-PLUS. Statistics and Computering. New York: Springer.

41. R Development Core Team (2009) A Language and Environment for Statistical Computing. Vienna: R Foundation for Statistical Computing.

42. Hothorn T, Bretz F \& Westfall P (2008) Simultaneous inference in general parametric models. Biom J 50, 346-363.

43. Pinheiro J, Bates D, DebRoy S et al. (2009) Linear and nonlinear mixed effects models. R package version 3.1-96.

44. Bellinger L, Lilley C \& Langley-Evans SC (2004) Prenatal exposure to a maternal low-protein diet programmes a preference for high-fat foods in the young adult rat. BrJ Nutr 92, 513-520.

45. Lussana F, Painter RC, Ocke MC, et al. (2008) Prenatal exposure to the Dutch famine is associated with a preference for fatty foods and a more atherogenic lipid profile. $A m \mathrm{~J}$ Clin Nutr 88, 1648-1652.

46. Vickers MH, Breier BH, Cutfield WS, et al. (2000) Fetal origins of hyperphagia, obesity, and hypertension and postnatal amplification by hypercaloric nutrition. Am J Physiol Endocrinol Metab 279, 83-E87.

47. Desai M, Babu J \& Ross MG (2007) Programmed metabolic syndrome: prenatal undernutrition and postweaning overnutrition. Am J Physiol Reg Integr Comp Physiol 293, R2306-R2314.

48. De Blasio MJ, Gatford KL, Robinson JS, et al. (2007) Placental restriction of fetal growth reduces size at birth and alters postnatal growth, feeding activity, and adiposity in the 
young lamb. Am J Physiol Reg Integr Comp Physiol 292, 875-886.

49. Bellinger L, Sculley DV \& Langley-Evans SC (2006) Exposure to undernutrition in fetal life determines fat distribution, locomotor activity and food intake in ageing rats. Int $J$ Obes (Lond) 30, 729-738.

50. Gabriely I, Ma XH, Yang XM, et al. (2002) Removal of visceral fat prevents insulin resistance and glucose intolerance of aging: an adipokine-mediated process? Diabetes $\mathbf{5 1}$ 2951-2958.

51. Fluharty FL \& McClure KE (1997) Effects of dietary energy intake and protein concentration on performance and visceral organ mass in lambs. J Anim Sci 75, 604-610.

52. Lobley GE (1993) Protein metabolism and turnover. In Quantitative Aspects of Ruminant Digestion and Metabolism, pp. 313-333 [JM Forbes and J France, editors]. Wallingford: CAB International.

53. Symonds ME, Budge H, Perkins AC, et al. (2011) Adipose tissue development - impact of the early life environment. Prog Biophys Mol Biol 106, 300-306.
54. Virtue S \& Vidal-Puig A (2010) Adipose tissue expandability, lipotoxicity and the metabolic syndrome - an allostatic perspective. Biochim Biophys Acta 1801, 338-349.

55. Purnell JQ, Kahn SE, Samuels MH, et al. (2009) Enhanced cortisol production rates, free cortisol, and 11beta-HSD-1 expression correlate with visceral fat and insulin resistance in men: effect of weight loss. Am J Physiol Endocrinol Metab 296, 351-357.

56. Mericq V, Medina P, Bouwman C, et al. (2009) Expression and activity of 11beta-hydroxysteroid dehydrogenase type 1 enzyme in subcutaneous and visceral adipose tissue of prepubertal children. Horm Res 71, 89-93.

57. Bloomfield FH, Oliver MH, Giannoulias CD, et al. (2003) Brief undernutrition in late-gestation sheep programs the hypothalamic-pituitary-adrenal axis in adult offspring. Endocrinology 144, 2933-2940.

58. Vieau D, Sebaai N, Léonhardt M, et al. (2007) HPA axis programming by maternal undernutrition in the male rat offspring. Psychoneuroendocrinology 32, Suppl. 1, S16-S20. 